\title{
Nutritional mode and specialization alter protist consumer diversity effects on prey assemblages
}

\author{
Joanna Filip*, Lilian-Lee Müller, Helmut Hillebrand, Stefanie Moorthi \\ Carl-von-Ossietzky University Oldenburg, Institute for Chemistry and Biology of the Marine Environment (ICBM), \\ Schleusenstrasse 1, Wilhelmshaven 26328, Germany
}

\begin{abstract}
Mixotrophy is a widespread phenomenon and plays an important role in aquatic food webs by increasing the complexity of trophic interactions and enhancing trophic transfer up the food web. Nevertheless, the effects of mixotrophic consumers on lower trophic levels have not been investigated in the framework of recent biodiversity and ecosystem functioning research, although mixotrophic interactions can lead to enhanced variability of those relationships. The effects of ciliate consumer diversity and nutritional mode on algal prey biovolume and evenness as well as consumer biovolume were investigated in 2 freshwater microcosm experiments. Different species compositions in the consumer and algal assemblages of the 2 experiments resulted in partially different interactions. Increasing consumer richness decreased prey biovolume in both experiments. However, heterotrophic consumers decreased prey biovolume and evenness more than mixotrophs in one experiment, driven by a strong grazer that was not present in the other experiment. Consumer presence and richness affected prey evenness differently, preventing competitive dominance among algae in one experiment but leading to unbalanced grazing in an initially more even prey assemblage in the other experiment. Secondary production increased with consumer richness in both experiments but was differently affected by the consumers' nutritional mode due to altered competitive interactions and niche overlap in different species combinations. The present study demonstrated that consumer-specific characteristics, such as nutritional mode and feeding preferences, may alter consumer diversity effects on prey.
\end{abstract}

KEY WORDS: Mixotrophy $\cdot$ Consumer diversity $\cdot$ Ecosystem functioning $\cdot$ Multitrophic $\cdot$ Traits · Food web $\cdot$ Ciliates $\cdot$ Microalgae

Resale or republication not permitted without written consent of the publisher

\section{INTRODUCTION}

In human-dominated ecosystems, an accelerating loss of species has been observed for decades, with potentially important consequences for ecosystem properties and processes (e.g. Hooper et al. 2005, Pereira et al. 2010, Cardinale et al. 2011). In this context, the consequences of biodiversity loss depend on the complexity and structure of ecosystems and on the number and identities of species or functional groups lost (e.g. Naeem et al. 1994, Tilman \& Downing 1994, Tilman et al. 2001).
Focusing on consumer diversity effects within and across trophic levels, Thébault \& Loreau (2003) demonstrated in a plant and consumer food web model that the degree of herbivore consumer specialization and thus food web connectivity was an important factor determining the relationship between consumer diversity and ecosystem functioning. Plant biomass was reduced faster with increasing generalist consumer diversity compared to specialized consumers, as the consumption rate on each prey species in the food web increased when generalists were added. However, consumer secondary production 
decreased at high generalist diversity, due to lower resource-use complementarity, but increased when specialists were present. This model was experimentally tested by J. Filip et al. (unpubl.), who manipulated ciliate consumer diversity and specialization in a freshwater microcosm to test their effects on the biovolume, evenness and composition of microalgal prey as well as on secondary production. In contrast to the model, specialist consumers had stronger negative effects on prey biovolume and evenness than generalists, which exerted a lower grazing pressure on their prey. However, these negative effects of the specialists were mainly driven by one consumer species, which exhibited much higher ingestion rates than the generalists. Secondary production increased with increasing consumer diversity, indicating a high resource use complementarity among specialists and generalists. These modeled and experimental results demonstrated that the degree of specialization and species-specific characteristics, such as growth and grazing rates, matter in determining diversity effects within and across trophic levels and provide a better understanding of diversity effects on ecosystem functioning.

In contrast to purely heterotrophic consumers exhibiting specific feeding preferences and grazing rates, mixotrophic protistan consumers, which are able to combine photosynthesis and phagotrophy (Sanders 1991, Stickney et al. 2000), can have very variable effects on their prey, which depend on biotic and abiotic factors that can influence their nutritional mode of gaining energy. In the context of consumer diversity effects on lower trophic levels, however, mixotrophic consumers and their interactions with other consumers and their prey have not to date been considered in biodiversity ecosystem functioning studies.

Mixotrophy is a widespread nutritional strategy that has been observed in a variety of protistan groups, such as ciliates, sarcodines and microalgae from virtually all aquatic environments (Sanders 1991, Riemann et al. 1995, Stoecker 1998). Primarily heterotrophic ciliates, for instance, may be able to use photosynthesis to gain energy by either harboring algal symbionts or sequestering chloroplasts from ingested algae (Sanders 1991). These mixotrophs can be very abundant in freshwater and marine systems and represent a crucial link between the microbial and classic food webs as potentially important consumers of algae and bacteria (Azam et al. 1983, Sanders 1991, Jones 1994). The contribution of photosynthesis and phagotrophy varies widely among mixotrophs and depends on species-specific charac- teristics as well as environmental factors such as light, dissolved nutrients and prey abundances (Jones 1994, Holen \& Boraas 1995). Due to their ability to act as primary producers and consumers of particulate organic matter, mixotrophs can act on 2 trophic levels, thus increasing the complexity of trophic interactions while enhancing trophic transfer up the food web (Sanders 1991, Ptacnik et al. 2004). The effects of species diversity on ecosystem functioning at any trophic level depend on the trophic structure of the food web (e.g. McGrady-Steed et al. 1997, Mikola 1998, Wardle 1999, Norberg 2000, J. Filip et al. unpubl.) and species specific characteristics (Thébault \& Loreau 2003, J. Filip et al. unpubl.). In this context, interactions of mixotrophic consumers and their prey may be different to and more complex than purely heterotrophic ones because mixotrophs can not only feed on their prey but also compete with it for nutrients. Their alternative nutritional strategies enhance trait diversity and may buffer the effect of species loss by providing alternative energy pathways, which may have a stabilizing effect on ecosystem functioning (Ptacnik et al. 2010).

The present study investigated the effects of ciliate consumer diversity and nutritional mode on prey and consumer dynamics in 2 microcosm experiments by allowing 2 heterotrophic and 2 mixotrophic ciliates in 3 diversity levels (1,2 and 4 species) to graze on a 4 -species algal mix. The following hypotheses were tested: (1) Increasing consumer richness decreases prey biovolume and evenness and changes species composition. (2) In this context, mixotrophic consumers have a weaker effect on prey biovolume and evenness than heterotrophic consumers because they gain part of their energy through photosynthesis. (3) Consumer richness increases secondary production and (4) is higher in treatments including mixotrophic consumers due to enhanced resource use complementarity.

\section{MATERIALS AND METHODS}

Two experiments were conducted using 2 different sets of 4 freshwater microalgae as prey and 2 heterotrophic (Expt 1: H1 and H2, Expt 2: H2 and H3) and 2 mixotrophic ciliates (M1 and M2) as consumers (Table 1). For Expt 1, we included the prey species Chlamydomonas terricola (A1), Cryptomonas sp. (A2), Fragilaria capucina (A3) and Eudorina elegans (A4), which were purchased from the Culture Collection of Algae (CCA) at the Botanical Institute of the University of Cologne, Germany. In Expt 2, we uti- 
Table 1. Ciliate and algal species and their combinations used in the 2 experiments. H1 to H3: heterotrophic consumers; M1 and M2: mixotrophic consumers; A1 to A6: algal prey; comb. id: combination identifier. Species may be referred to in this article by genus name alone

\begin{tabular}{|c|c|c|c|c|c|c|c|c|}
\hline & \multirow{2}{*}{$\begin{array}{l}\text { Comb. } \\
\text { id }\end{array}$} & \multirow{2}{*}{$\begin{array}{c}\text { C } \\
\text { No. of } \\
\text { species }\end{array}$} & \multirow{2}{*}{$\begin{array}{l}\text { iliate species combination } \\
\text { Species }\end{array}$} & \multirow[b]{2}{*}{$\begin{array}{l}\text { Species } \\
\text { code }\end{array}$} & \multirow[b]{2}{*}{$\begin{array}{l}\text { Comb. } \\
\text { id }\end{array}$} & \multirow{2}{*}{$\begin{array}{c}\text { Alg } \\
\text { No. of } \\
\text { species }\end{array}$} & \multirow{2}{*}{$\begin{array}{l}\text { gal species combination } \\
\text { Species }\end{array}$} & \multirow[b]{2}{*}{$\begin{array}{l}\text { Species } \\
\text { code }\end{array}$} \\
\hline & & & & & & & & \\
\hline \multirow[t]{11}{*}{ Expt 1} & 1 & 1 & Frontonia angusta & $\mathrm{H} 1$ & 0 & 4 & Chlamydomonas terricola & A1 \\
\hline & 2 & 1 & Stylonychia sp. & $\mathrm{H} 2$ & & & Cryptomonas sp. & $\mathrm{A} 2$ \\
\hline & 3 & 1 & Euplotes daidaleos & M1 & & & Fragilaria capucina & A3 \\
\hline & 4 & 1 & Coleps sp. & M2 & & & Eudorina elegans & $\mathrm{A} 4$ \\
\hline & 5 & 2 & Frontonia + Stylonychia & $\mathrm{H} 1+\mathrm{H} 2$ & & & & \\
\hline & 6 & 2 & Frontonia + Euplotes & $\mathrm{H} 1+\mathrm{M} 1$ & & & & \\
\hline & 7 & 2 & Frontonia + Coleps & $\mathrm{H} 1+\mathrm{M} 2$ & & & & \\
\hline & 8 & 2 & Stylonychia + Euplotes & $\mathrm{H} 2+\mathrm{M} 1$ & & & & \\
\hline & 9 & 2 & Stylonychia + Coleps & $\mathrm{H} 2+\mathrm{M} 2$ & & & & \\
\hline & 10 & 2 & Euplotes + Coleps & $\mathrm{M} 1+\mathrm{M} 2$ & & & & \\
\hline & 11 & 4 & $\begin{array}{l}\text { Frontonia + Stylonychia } \\
+ \text { Euplotes + Coleps }\end{array}$ & $\begin{array}{r}\mathrm{H} 1+\mathrm{H} 2+ \\
\mathrm{M} 1+\mathrm{M} 2\end{array}$ & & & & \\
\hline \multirow[t]{11}{*}{ Expt 2} & 13 & 1 & Stylonychia sp. & $\mathrm{H} 2$ & 12 & 4 & Chlamydomonas terricola & A1 \\
\hline & 14 & 1 & Nassula sorex & H3 & & & Cryptomonas sp. & $\mathrm{A} 2$ \\
\hline & 15 & 1 & Euplotes daidaleos & M1 & & & Navicula pelliculosa & A5 \\
\hline & 16 & 1 & Coleps sp. & M2 & & & Plectonema sp. & $\mathrm{A} 6$ \\
\hline & 17 & 2 & Stylonychia + Nassula & $\mathrm{H} 2+\mathrm{H} 3$ & & & & \\
\hline & 18 & 2 & Stylonychia + Euplotes & $\mathrm{H} 2+\mathrm{M} 1$ & & & & \\
\hline & 19 & 2 & Stylonychia + Coleps & $\mathrm{H} 2+\mathrm{M} 2$ & & & & \\
\hline & 20 & 2 & Nassula + Euplotes & $\mathrm{H} 3+\mathrm{M} 1$ & & & & \\
\hline & 21 & 2 & Nassula + Coleps & $\mathrm{H} 3+\mathrm{M} 2$ & & & & \\
\hline & 22 & 2 & Euplotes + Coleps & $\mathrm{M} 1+\mathrm{M} 2$ & & & & \\
\hline & 23 & 4 & $\begin{array}{l}\text { Stylonychia + Nassula } \\
+ \text { Euplotes }+ \text { Coleps }\end{array}$ & $\begin{array}{r}\mathrm{H} 2+\mathrm{H} 3+ \\
\mathrm{M} 1+\mathrm{M} 2\end{array}$ & & & & \\
\hline
\end{tabular}

lized the algae A1 and A2 as in Expt 1 but replaced the species A3 and A4 with the diatom Navicula pelliculosa (A5) and the cyanobacteria Plectonema sp. (A6). The latter was purchased from the Culture Collection of Algae and Protozoa (CCAP), Institute of Freshwater Ecology, Cumbria, UK, together with the heterotrophic consumer Nassula sorex (H3), while $N$. pelliculosa (A5) was supplied by U.-G. Berninger, University of Salzburg, Austria, together with the heterotrophic consumer Frontonia sp. (H1) and the mixotroph Coleps sp. (M2). The other mixotrophic consumer, Euplotes daidaleos (M1), was provided by P. Morin, Rutgers University, New Brunswick, NJ, USA, while the heterotrophic ciliate Stylonychia sp. (H2) was isolated from a pond close to the University of Cologne, Germany. The mixotrophic ciliates Euplotes and Coleps both contain the chlorophyte Chlorella as permanent symbionts (Diller \& Kounaris 1966, Jones 2000). However, the contribution of photosynthesis and phagotrophy varies among these mixotrophs; photosynthesis plays a more important role for the nutrition of Coleps than for Euplotes, which is primarily heterotrophic (S. Moorthi unpubl. data).
All organisms used in the experiments are common freshwater species and represent a wide range of different taxonomic groups. Cultures were kept in transparent tissue culture flasks (BD Falcon, culture flasks with filter caps, total growth area: $25 \mathrm{~cm}^{2}$, volume: $50 \mathrm{ml}$ ) in a climate chamber at $18^{\circ} \mathrm{C}$ with a light/dark cycle of 12:12 $\mathrm{h}$ and a light intensity of $60 \mu \mathrm{mol} \mathrm{m} \mathrm{m}^{-2} \mathrm{~s}^{-1}$ (LI-COR LI-193). The algae were cultivated in WEES culture medium (McFadden \& Melkonian 1986), while the ciliates were grown in mineral water (Volvic) and fed weekly with the cryptophyte A2, except for Nassula sorex, which was fed with the filamentous cyanobacterium A6 (Table 1).

In both experiments, consumer richness was manipulated by establishing 3 different consumer diversity levels comprising consumer monocultures $(n=4)$, all possible 2-species combinations $(\mathrm{n}=6)$ and a 4 -species combination $(n=1)$. These 11 different ciliate species combinations all fed on a constant mixture of all 4 algal species. A 4 -species algal mixture without consumers served as a control. All treatments (12) were replicated 4 times, resulting in a total of $48 \mathrm{ex}-$ perimental units in each experiment. Ciliates and algae were initially inoculated with equal biovolumes 
at the beginning of the experiments (Expt 1: algal

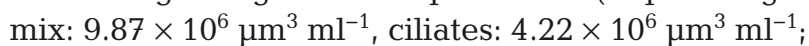

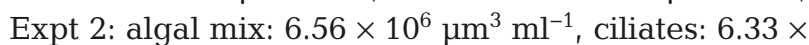

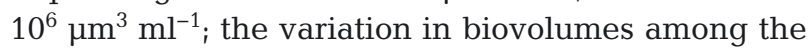
experiments resulted from different development states of the initial cultures), i.e. for ciliate 2-species or 4-species combinations, the total biovolume of individual consumer species was halved or quartered, respectively. To convert culture cell counts to biovolumes, average individual biovolumes of algal and ciliate species were determined by measuring cell lengths and widths of 20 individual cells per species utilizing an inverted microscope (Zeiss, Axiovert 100) at $100 \times$ for ciliates and $400 \times$ magnification for algae. Cell biovolumes were calculated according to defined geometric shapes approximating the cell shapes of different species sensu Hillebrand et al. (1999) and Moorthi et al. (2008). Organisms were measured alive before preservation because they can change their shape after fixation (Stoecker et al. 1994).

After inoculation of the communities in WEES medium (McFadden \& Melkonian 1986), the experiments were sampled every third day for an experimental duration of $15 \mathrm{~d}$ (Expt 1) and $16 \mathrm{~d}$ (Expt 2) by taking $10 \mathrm{ml}$ subsamples from each experimental unit. Samples were preserved with Lugol's iodine solution at $1 \%$ final concentration for counting, and the sampled volume was replaced by new culture medium. For each sampling time point, cell abundances were determined by microscopy in each experimental unit using the Utermöhl technique (Utermöhl 1958), counting a minimum of 300 individuals for algae and 50 individuals for ciliates. Cell counts were transformed into biovolume $\mathrm{ml}^{-1}$.

The cultures used in the experiments were not axenic. Because we ran both experiments as semi- continuous cultures, replacing the sampled volume with new full medium every third day $(10 \mathrm{ml}, 7 \%$ of the total experimental volume), we assume that nutrient limitation did not play a major role for the algal assemblages and that a potential competition for nutrients between algae and bacteria could be neglected in the context of our study. All of the ciliates used in our experiments were mainly herbivorous, and none of them were able to survive purely on bacteria, except for Euplotes daidaleos. This species, however, showed high algal ingestion rates and grew much faster when fed with algae. Therefore, it was also assumed to be mainly herbivorous, allowing us to neglect ciliate bacterivory in the context of our study and to focus on ciliate and phytoplankton interactions.

Both experiments were conducted as described above but utilized partly different algal and ciliate species and thus different food web configurations entailing different species interactions (Table 1, Fig. 1). For Expt 2, we could not avoid altering both the prey and predator composition because we wanted to replace the specialized consumer Frontonia due to its high specific grazing rates and thus strong negative effects on prey in the first experiment, which potential masked effects of the consumer's nutritional mode. Therefore, we replaced Frontonia, as compared to Expt 1, with another consumer specialist (Nassula), which necessarily led to a change in prey composition because Nassula is specialized on the cyanobacteria Plectonema. This species was included instead of the chlorophyte Eudorina in Expt 2. Furthermore, the diatom Fragilaria was replaced with the diatom Navicula because the Fragilaria culture was not in a healthy state at the time of the second experiment.
Experiment 1

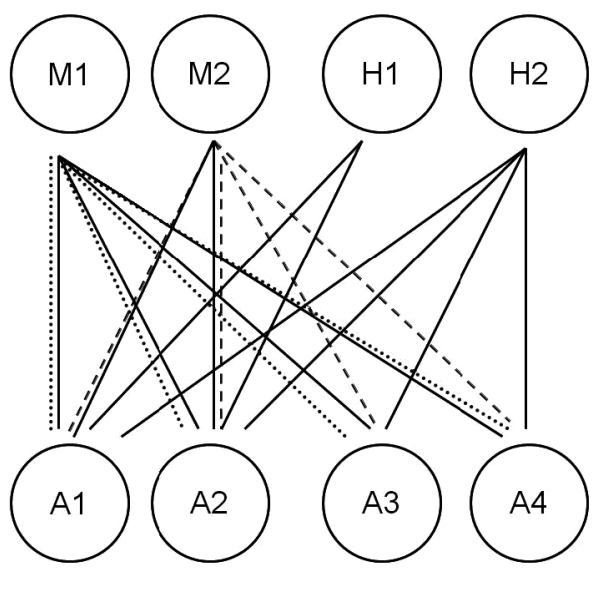

Experiment 2

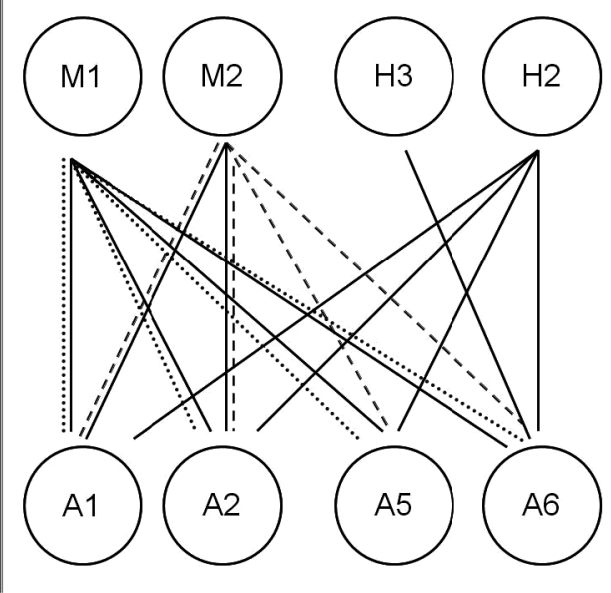

Fig. 1. Food web configurations of Expts 1 and 2 indicating the interactions between heterotrophic and mixotrophic consumers and their prey. Solid lines: grazing only, dashed lines: grazing and weak competitive interactions, dotted lines: grazing and strong competitive interactions. Full species names of abbreviated algal and consumer species are given in Table 1 
We analyzed data from 3 different sampling days (after 3, 9 and 15 or 16 d). However, only data from the last sampling day (Day 15 or 16), where we found the strongest effects, are presented. Effects with similar trends could also be detected on the prior sampling days but were not significant.

The variances were not homogeneous even after data transformation (which is a premise for an analysis of variance). Therefore, non-parametric tests (Kruskal-Wallis) were conducted for both experiments to determine the effects of consumer species combination on algal biovolume and evenness. In cases of a significant treatment effect, planned comparisons were used to compare the effects of selected consumer treatment groups: (1) algal mixture without consumers versus consumer-containing treatments, testing for an effect of ciliate presence on algal biovolume and evenness; (2) 1-species treatments versus all polycultures and (3) 2-species combinations versus 4 -species combinations, both testing for a consumer richness effect on algal biovolume and evenness; (4) purely heterotrophic versus purely mixotrophic species treatments; and (5) heterotrophic and mixotrophic species treatments versus all mixed treatments, respectively, both testing for differences in the effects on algal biovolume and evenness among differently specialized consumers.

The same analysis (including the same planned comparisons, except for the first one) was conducted to test for the effects of consumer species combination on secondary production (ciliate biovolume at the end of the experiments). For all of these analyses, sequential Bonferroni adjustment was used to correct the Type I error due to repeated testing (Rice 1989). Due to the conservative nature of Bonferroni adjustments, treatment effects with $\mathrm{p}<0.1$ are discussed as trends.

To analyze the mechanisms driving consumer diversity effects on secondary production, net biodiversity effects (NBE) were calculated and partitioned in both experiments for each treatment into dominance effect (DE), and trait-dependent and trait-independent complementarity effects (TDC and TIC) sensu Fox (2005). A positive TDC effect indicates that species with a larger niche breadth will benefit in mixtures due to reduced competition, but not at the expense of other species. Positive TICs prevail when all species produce higher yields in mixtures than in monoculture due to nonoverlapping niches (mutual complementarity effect), while interspecific competition for prey species due to overlapping niches leads to a negative TIC.
When the most productive species performs best in monoculture as well as in a mixture and excludes other species by reducing their prey, a positive DE occurs.

Again, variances were not homogeneous even after data transformation, and therefore, a non-parametric test (Kruskal-Wallis) was conducted to determine the effect of consumer species combination on the different biodiversity effects. For this analysis, we also used a priori planned comparisons to compare the effects of the following consumer treatment groups: (1) 2-species combinations versus 4 -species combinations, testing for a consumer richness effect on consumer biovolume, (2) purely heterotrophic versus purely mixotrophic species treatments and (3) purely heterotrophic and purely mixotrophic species treatments versus all mixed treatments (containing both heterotrophic and mixotrophic consumers), respectively, both testing for differences in effects on consumer biovolume among differently specialized consumers. Sequential Bonferroni adjustment accounted for the Type I error due to repeated testing (Rice 1989).

\section{RESULTS}

\section{Effects of consumer diversity and nutritional mode on prey biovolume and evenness}

\section{Biovolume}

Consumer presence decreased prey biovolume in both experiments, but after Bonferroni adjustment this effect was only significant for Expt 2 (Fig. 2a, Table 2; planned comparisons 1 and 7). When consumers were added, prey biovolume decreased with increasing consumer diversity in both experiments, but again consumer diversity effects were only significant for Expt 2 (Fig. 2a, Table 2; planned comparison 8), while only a trend was observable for Expt 1 after Bonferroni adjustment (Fig. 2a, Table 2; planned comparisons 2 and 3). Consumer nutritional mode affected prey biovolume in Expt 1, as biovolume was significantly lower in treatments containing purely heterotrophic consumers than in combined treatments and highest in treatments containing mixotrophic consumers. These effects could only be observed as trends after Bonferroni adjustment (Fig. 2a, Table 2; planned comparisons 5 and 6), while there were no significant effects at all in Expt 2 (Fig. 2a, Table 2; planned comparisons 10-12). 

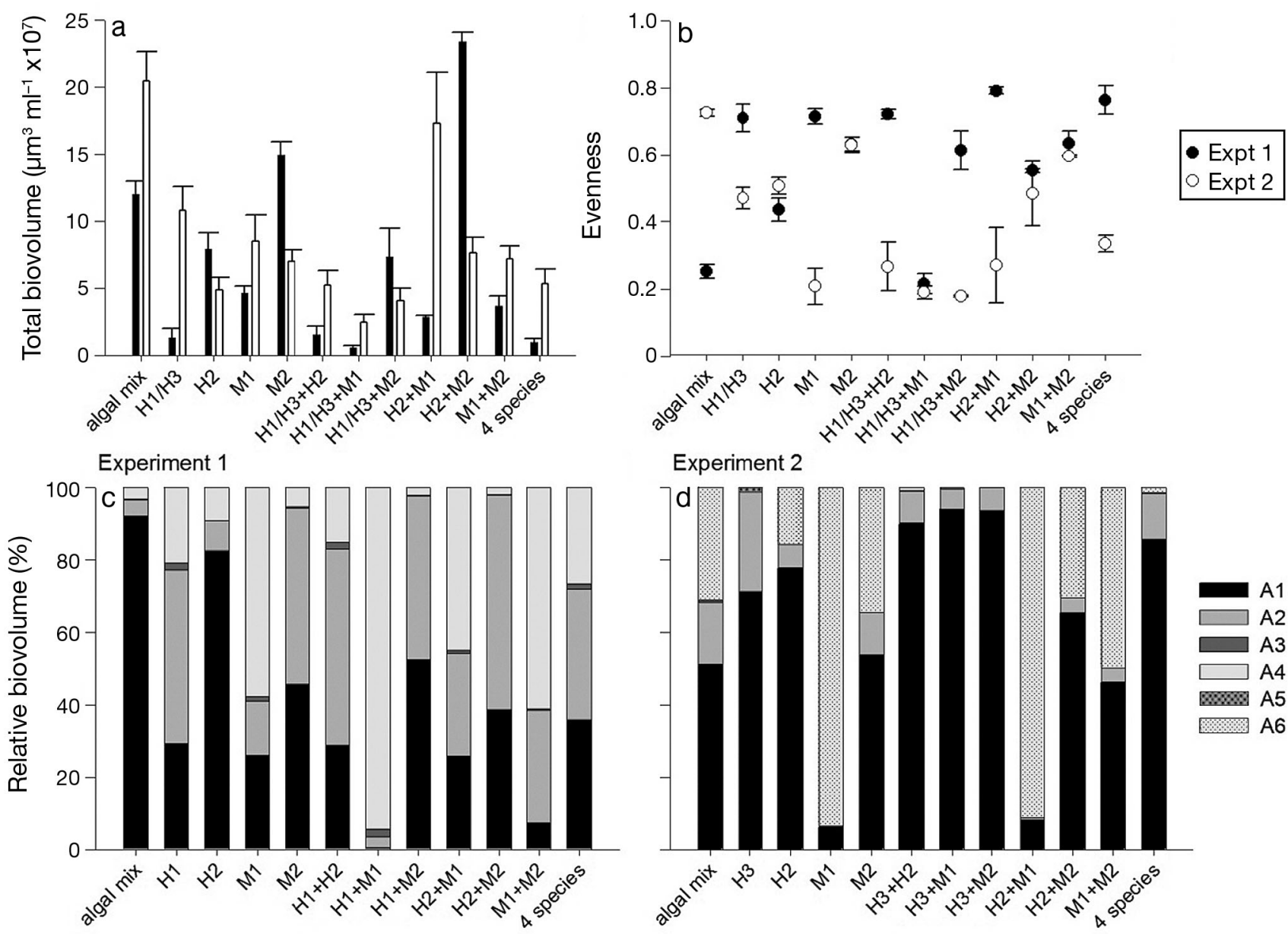

\section{Experiment 2}

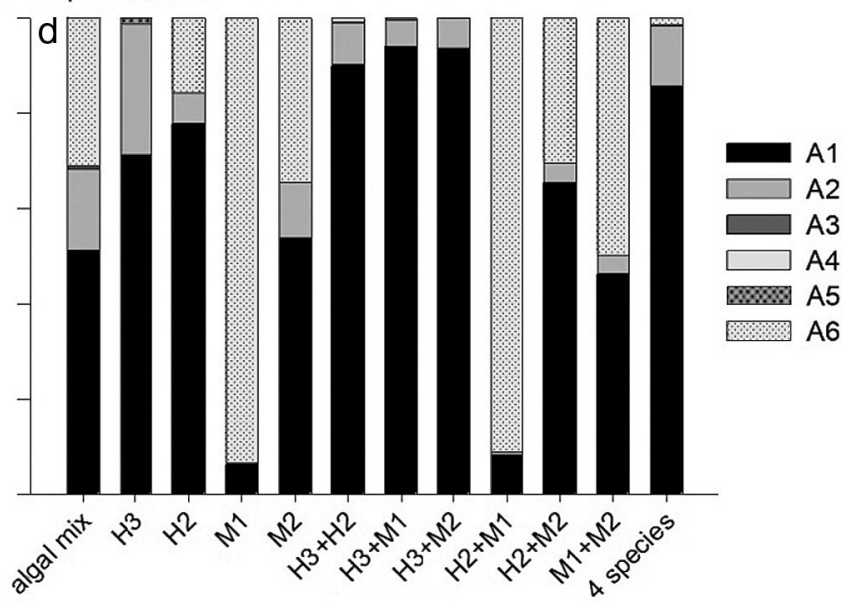

Treatment

Fig. 2. (a) Total and (c,d) relative prey biovolume and (b) prey evenness in the different consumer species combinations in both experiments. Error bars in (a) and (b) show mean and standard deviation

\section{Evenness}

Consumer presence had significant effects on prey evenness; however, the effects differed between experiments (Fig. 2b, Table 2; planned comparisons 1 and 7 ). While the consumer presence and richness increased prey evenness in Expt 1, it decreased evenness in Expt 2 (Fig. 2b, Table 2; planned comparisons 1-3 for Expt 1 and 7-9 for Expt 2; non-significant trend after Bonferroni for Expt 1 in planned comparisons 2 and 3). In Expt 1, Chlamydomonas terricola (A1) dominated the prey assemblage when consumers were absent (Fig. 2c), while in the presence of consumers, the algal species were more evenly distributed. In contrast, the prey assemblage in Expt 2 was more even in the absence of consumers, while mainly the chlorophyte Chlamydomonas (A1) and the cyanobacteria Plectonema sp. (A4) dominated the prey assemblages when consumers were present, resulting in a lower evenness (Fig. 2d).
Besides consumer diversity, consumer nutritional mode affected prey evenness significantly in Expt 2, where algal evenness was highest in purely mixotrophic and lowest in combined treatments (treatments containing both nutritional modes; Fig. 2b, Table 2; planned comparisons 10 and 11). Consumer nutritional mode had no significant effects on prey evenness in Expt 1.

\section{Effects of consumer diversity and nutritional mode on secondary production}

In Expt 1, neither consumer diversity nor the consumers' nutritional mode significantly affected secondary production (Fig. 3a, Table 2). However, the heterotrophic consumer Frontonia angusta (H1) dominated all consumer assemblages when included. In these consumer species combinations, the highest total biovolumes were observed, indicating that this 
Table 2. Results of a non-parametric Kruskal Wallis test on the effects of consumer species combination on algal biovolume and evenness as well as on consumer biovolume for Expts 1 and 2. Associated planned comparisons compare the effects of selected consumer treatment groups for both experiments. 'All polycultures' refers to treatments including $>1$ consumer species, while 'mixed treatments' refers to polycultures including heterotrophic and mixotrophic consumers. The numbers in the columns defining the planned comparisons refer to the particular consumer species combinations that were tested (see Table 1). ${ }^{* * *}$ Significant after Bonferroni adjustment, ${ }^{*}$ trend (see 'Materials and methods')

\begin{tabular}{|c|c|c|c|c|c|c|}
\hline & \multirow[b]{2}{*}{ df } & $\begin{array}{c}\text { Prey } \\
\text { Biovolume }\end{array}$ & \multirow{2}{*}{$\begin{array}{c}\text { Evenness } \\
\mathrm{p}\end{array}$} & \multicolumn{2}{|c|}{$\begin{array}{l}\text { Consumer } \\
\text { biovolume }\end{array}$} \\
\hline & & & $\mathrm{p}$ & & df & $\mathrm{p}$ \\
\hline \multicolumn{7}{|c|}{ Experiment 1} \\
\hline Kru & kal-Wallis & 11,36 & $<0.001$ & $<0.001$ & 10,43 & $<0.001$ \\
\hline \multicolumn{7}{|c|}{ Planned comparison } \\
\hline 1 & Consumer present (1-11) vs. consumer absent (0) & 1,47 & $0.037^{*}$ & $0.005^{* * *}$ & & \\
\hline & 1 species treatments (1-4) vs. all polycultures (5-11) & 1,43 & $0.027^{*}$ & $0.02^{*}$ & 1,43 & 0.591 \\
\hline 3 & 2 species $(5-10)$ vs. 4 species $(11)$ & 1,27 & $0.017^{*}$ & 0.058 & 1,27 & 0.061 \\
\hline 4 & Mixotrophs $(3,4,10)$ vs. all mixed treatments $(6-9,11)$ & 1,31 & 0.215 & 0.428 & 1,31 & 0.567 \\
\hline 5 & Heterotrophs $(1,2,5)$ vs. all mixed treatments vs. $(6-9,11)$ & 1,31 & $0.014^{*}$ & 0.714 & 1,31 & 0.567 \\
\hline 6 & Mixotrophs $(3,4,10)$ vs. heterotrophs $(1,2,5)$ & 1,23 & $0.04^{*}$ & 0.414 & 1,23 & 0.837 \\
\hline \multicolumn{7}{|c|}{ Experiment 2} \\
\hline Kru & kal-Wallis & 11,36 & 0.001 & 0.001 & 10,43 & $<0.001$ \\
\hline \multicolumn{7}{|c|}{ Contrast } \\
\hline 7 & Consumer present (13-23) vs. consumer absent (12) & 1,47 & $0.005^{* * *}$ & $0.001^{* * *}$ & & \\
\hline 8 & 1 -species treatments $(13-16)$ vs. all polycultures $(17-23)$ & 1,43 & $0.01^{* * *}$ & $0.001^{* * *}$ & 1,43 & $0.048^{*}$ \\
\hline 9 & 2 species $(17-22)$ vs. 4 species $(23)$ & 1,27 & 0.108 & $0.016^{* * *}$ & 1,27 & $0.003^{* * *}$ \\
\hline 10 & Mixotroph $(15,16,22)$ vs. all mixed treatments $(18-21,23)$ & 1,31 & 0.310 & $0.01^{* * *}$ & 1,31 & $0.002^{* * *}$ \\
\hline & Heterotroph $(13,14,17)$ vs. all mixed treatments $(18-21,23)$ & 1,31 & 0.071 & $0.03^{*}$ & 1,31 & $0.002^{* * *}$ \\
\hline & Mixotroph $(15,16,22)$ vs. heterotroph $(13,14,17)$ & 1,23 & 0.691 & 0.407 & 1,23 & $0.002^{* * *}$ \\
\hline
\end{tabular}
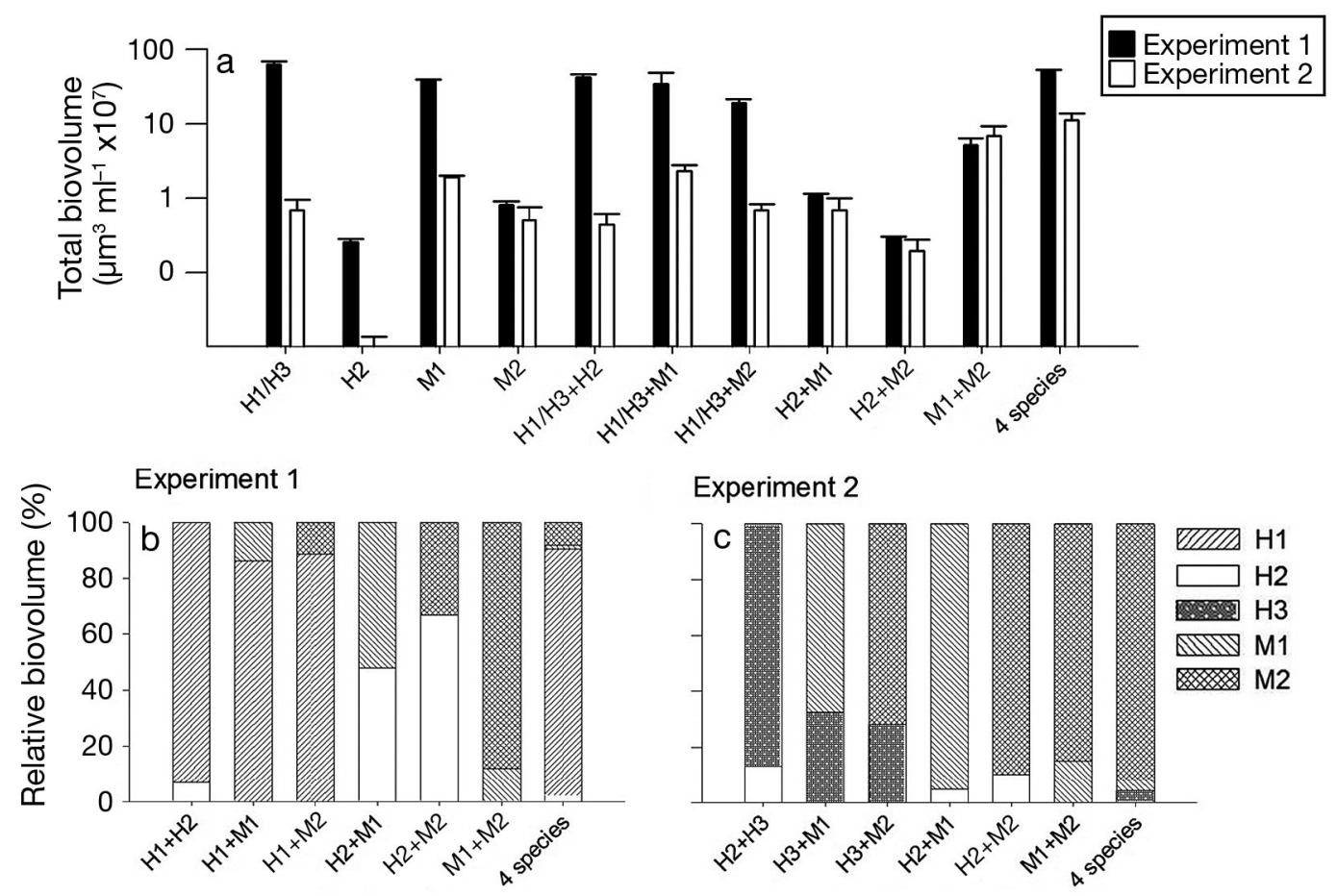

Experiment 2

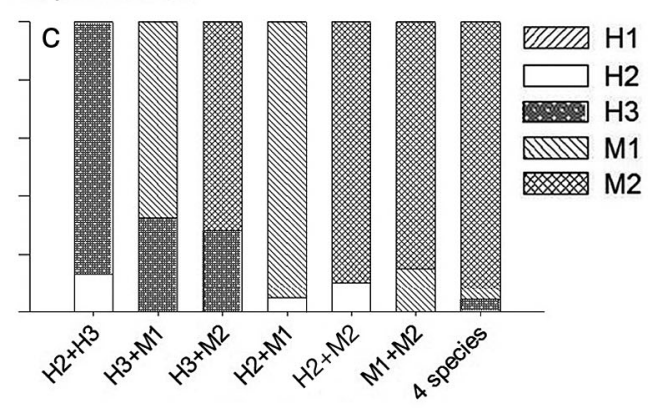

Treatment

Fig. 3. (a) Total and $(b, c)$ relative consumer biovolumes in the different consumer species combinations in both experiments. Error bars in (a) show mean and standard deviation 
particular species was an important determinant of secondary production in this experiment (Fig. 3b). In Expt 2, however, in which Frontonia was exchanged for another consumer specialist (Nassula sorex), secondary production significantly increased with increasing consumer diversity (Fig. 3a, Table 2; planned comparisons 8 and 9). Furthermore, treatments containing only mixotrophic, only heterotrophic and both kinds of ciliates all significantly differed from each other. While treatments containing purely mixotrophic consumers reached the highest biovolumes, secondary production was lowest in treatments containing purely heterotrophic ciliates (Fig. 3a, Table 2; planned comparisons 10-12). Both mixotrophs dominated over the heterotrophic consumers in mixed combinations, and the mixotrophic consumer Coleps (M2) also dominated over the other mixotroph Euplotes (M1) and in the 4-species combination (Fig. 3c).

\section{Tripartitioning of biodiversity effects}

In both experiments, a positive net biodiversity effect of consumer diversity on consumer biovolume was found (Fig. 4a,e; Kruskal Wallis, Expt 1: p = 0.001; Expt 2: $\mathrm{p}=0.005)$. The tripartite partitioning of these positive net biodiversity effects resulted in negative TDC and DE effects, and a positive TIC in both experiments, which were all significantly different from zero (Fig. 4 ; $t$-test, TDC: $\mathrm{p}<0.001$; TIC: $\mathrm{p}<$ 0.001; DE: $\mathrm{p}<0.001$ ).

Consumer richness significantly increased the net biodiversity effects in both experiments (Fig. 4a, e; planned comparisons of 2 species vs. 4 species, Expt 1: $\mathrm{p}=0.006 ;$ Expt 2: $\mathrm{p}=0.002$ ) as well as the TIC effect (Fig. 4b, $f_{i}$ planned comparisons of 2 species vs. 4 species, Expt 2: $\mathrm{p}=0.003 ;$ Expt 1: $\mathrm{p}=$ 0.018 , non-significant trend after Bonferroni adjustment for Expt 1). In contrast, the negative TDC effect signifi-

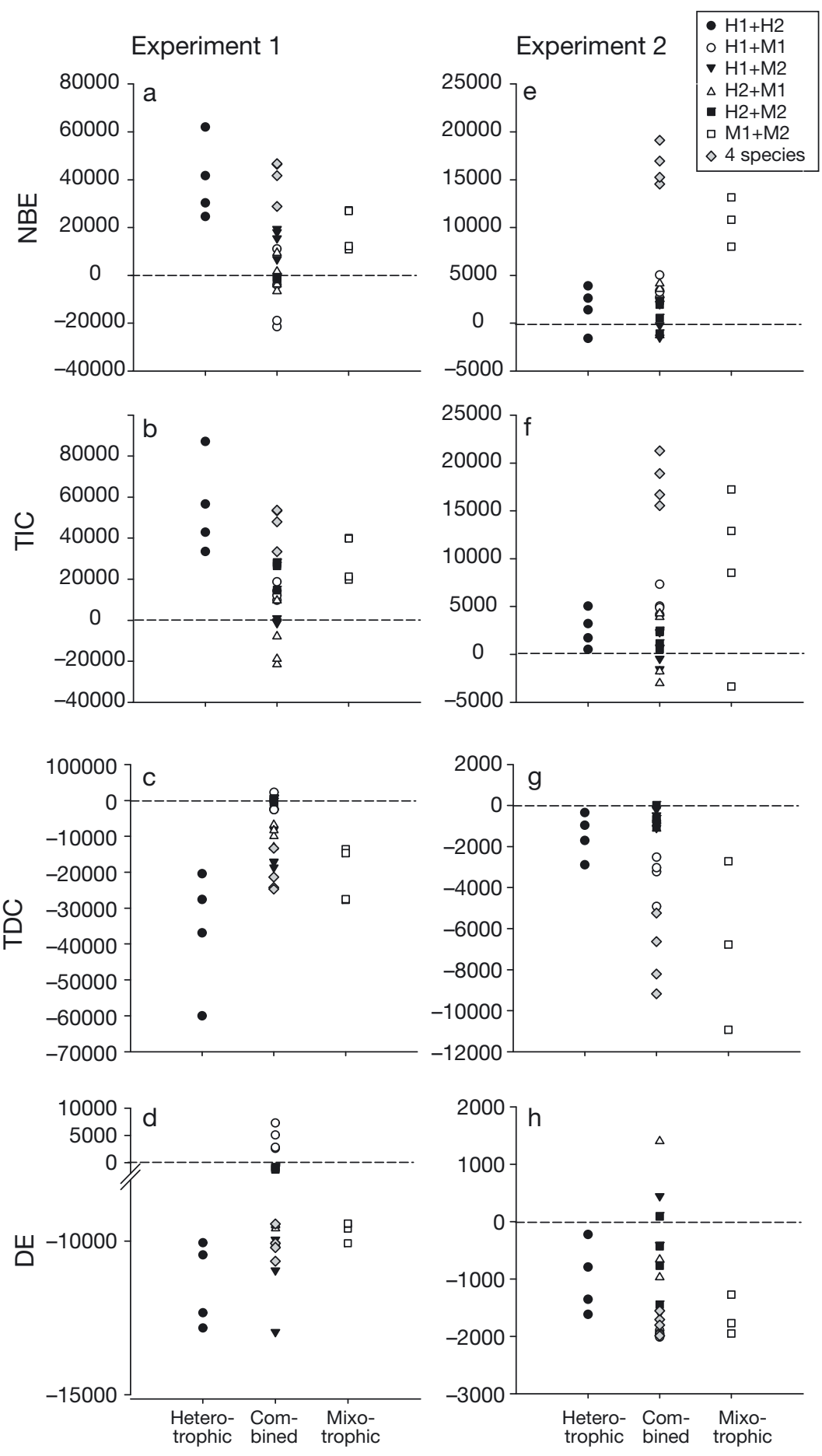

Fig. 4. Partitioned biodiversity effects of consumer richness on consumer biovolume. $(\mathrm{a}, \mathrm{e})$ Net biodiversity effect $(\mathrm{NBE}) ;(\mathrm{b}, \mathrm{f})$ trait-independent complementarity (TIC); $(\mathrm{c}, \mathrm{g})$ trait-dependent complementarity (TDC) and $(\mathrm{d}, \mathrm{h})$ dominance effect (DE) plotted against purely heterotrophic, purely mixotrophic and mixed consumer (heterotrophs and mixotrophs) treatments for both experiments (Expt 1: left panel, Expt 2: right panel). Positive TIC: mutual complementarity, negative TIC: interspecific competition; positive TDC: 1-way complementarity, negative TDC: species with nested niches perform better in mixtures than in monocultures; positive DE: lack of niche differentiation (species with high monoculture yields, dominate mixture), negative DE: species with low monoculture yields dominate mixture 
cantly decreased with richness but only in Expt 2 (Fig. 4g; $\mathrm{p}=0.008$ ). The consumers' nutritional mode significantly affected all biodiversity effects in Expt 1; however, only effects on TIC and TDC were significant after Bonferroni adjustment (Fig. 4b,c; planned comparisons of heterotrophs vs. all combined treatments: NBE, $p=0.02 ; \mathrm{DE}, \mathrm{p}=0.03, \mathrm{TIC}, \mathrm{p}=0.008$; TDC, $p=0.004$; mixotrophs vs. combined treatments: TDC, $p=0.03$; mixotrophs vs. heterotrophs DE, $p=$ 0.049 ). The negative TDC effects were significantly higher in combined treatments compared to purely mixotrophic and lowest for purely heterotrophic treatments, while the positive TIC and NBE effects were highest for purely heterotrophic treatments and lowest for combined treatments (Fig. 4). For Expt 2, no significant effects of the consumers' nutritional mode on biodiversity effects could be detected.

In both experiments, the negative DE was not significantly affected by consumer richness or nutritional mode.

\section{DISCUSSION}

\section{Increasing consumer richness decreases prey biovolume and evenness (Hypothesis 1)}

Consumer presence and richness decreased prey biovolume in both experiments (confirming Hypothesis 1). Negative consumer diversity effects on prey biovolume were demonstrated in different aquatic systems (e.g. Naeem \& Li 1998, Duffy et al. 2003, Gamfeldt et al. 2005, J. Filip et al. unpubl.), as consumer diversity increases prey consumption and the probability of including consumers with a wider feeding spectrum, thus enhancing complementary resource use (Gamfeldt et al. 2005, Finke \& Snyder 2008).

Prey evenness was decreased by consumer presence and richness in Expt 2 but increased in Expt 1. Depending on both the nature of competition among the prey species and consumer grazing, both positive (e.g. Proulx et al. 1996, Shurin 2001, Hillebrand 2003) and negative (Jaschinski et al. 2010) effects of consumer presence on evenness have been demonstrated in earlier studies. A positive effect occurs when grazers decrease dominant prey species, thus preventing competitive domination, while a negative effect occurs if consumers increase the prey's overall mortality rate in a more even prey assemblage (Hillebrand \& Shurin 2005). Here, in Expt 1, the chlorophyte Chlamydomonas terricola dominated the prey assemblage in the absence of consumers, while it was grazed when consumers were added, thus preventing competitive dominance of this species, leading to a more even prey composition. In Expt 2, however, 2 algal prey species and 1 consumer species were exchanged, leading to altered competitive dynamics among the algae and altered grazing pressure. The exchange of the 2 diatoms did not seem to make a difference in the dynamics of the 2 experiments, and both species were hardly present by Day 15 ; they were both outcompeted in the algal mixture without consumers and/or grazed in the treatments with consumers. The replacement of Eudorina by Plectonema in Expt 2, however, led to a more even prey distribution in the algal mixtures without consumers, as Plectonema apparently prevented Chlamydomonas from dominating the algal assemblage, as was the case in Expt 1. When consumers were added, prey evenness decreased, likely due to altered competitive interactions among the prey and altered grazing pressure by the ciliates. The consumer Frontonia angusta, which fed on Chlamydomonas and the cryptophyte Cryptomonas sp. in Expt 1, was replaced by the specialist consumer Nassula sorex in Expt 2, which only fed on the cyanobacteria Plectonema sp. In the absence of Nassula, the cyanobacteria Plectonema dominated the prey assemblage, indicating a weak grazing pressure by the other consumers. Thus, altered consumer composition led to a less balanced grazing pressure, decreasing prey evenness in the initially more even prey assemblage. These results indicate that the loss of a specialized consumer species can lead to a critical dominance of one particular prey species. In natural cyanobacteria dominated systems, for instance, algal bloom dynamics strongly depend on selective grazing (e.g. see review by Gragnani et al. 1999). Especially filamentous forms can only be successfully grazed by particular consumers, such as daphnids (Gobler et al. 2007). Therefore, in case of consumer diversity loss, unbalanced grazing may lead to strong bloom formation, which may severely affect the whole aquatic system (e.g. Chan et al. 2004).

\section{Mixotrophic consumers have a weaker effect on prey biovolume and evenness than heterotrophic consumers (Hypothesis 2)}

Even though the consumers' nutritional mode did not have any significant effects on prey biovolume in both experiments (refuting Hypothesis 2), there was a trend in Expt 1 indicating a stronger decrease in algal biovolume in purely heterotrophic treatments 
compared to combined treatments and the lowest decrease of prey biovolume in purely mixotrophic treatments. In a previous study, the ciliate consumer Frontonia was shown to have very high grazing rates and to be able to substantially decrease prey biovolume (J. Filip et al. unpubl.). Therefore, the trends observed in Expt 1 were mainly driven by high species-specific grazing rates of Frontonia. The replacement of this species with another specialist consumer (Nassula sorex) in Expt 2 resulted in no observable effects of consumer nutritional mode on prey biovolume, indicating that mixotrophs may have a similar grazing effect on a prey assemblage compared to heterotrophs and that species-specific traits, such as grazing rates of particular species, determine these effects more than consumer's nutritional mode per se. Confirming these results, Stickney et al. (2000) demonstrated in a mathematical model that effects of mixotrophic ciliate consumers on primary production were highly dependent on the mixotroph's specific traits, such as nutrient uptake dynamics as well as growth and grazing rates.

Consumer nutritional mode significantly affected prey evenness only in Expt 2. Here, evenness was higher in purely mixotrophic or purely heterotrophic treatments compared to combined treatments. In purely mixotrophic treatments, the cyanobacteria Plectonema sp. mainly dominated the prey assemblage, whereas the presence of only heterotrophic consumers (especially the specialist Nassula) resulted in a decrease of the cyanobacteria and a dominance of the chlorophyte Chlamydomonas, which became even stronger in combined treatments. However, our results gave no clear insights whether this was due to less balanced grazing pressure, competitive interactions between algae and mixotrophs or both.

\section{Consumer richness increases secondary production (Hypothesis 3)}

Secondary production increased with consumer diversity in Expt 2. Although the consumer species combination significantly affected secondary production in both experiments, these effects were not driven by increasing consumer diversity in Expt 1 . Contrary to our expectations, some monocultures in Expt 1 had equal or even higher biovolumes than the polycultures, thus not revealing increased secondary production with increasing richness (no transgressive overyielding; Trenbath 1974). Nevertheless, positive net biodiversity effects were observed for
Expt 1, which increased with increasing consumer richness, indicating a more efficient biovolume production in diverse assemblages than expected from monoculture yields in Expt 1 (non-transgressive overyielding). Similar effects were found in a 1 trophic level system in which microalgal diversity, resource supply and resource ratios were manipulated, revealing that resource partitioning or facilitation in mixtures resulted in higher-than-expected productivity at high resource supply, although no transgressive overyielding within the diverse assemblages occurred (Gamfeldt \& Hillebrand 2011).

Enhanced secondary production with increasing consumer diversity (as shown in Expt 2) was demonstrated for different systems, such as microbial microcosms (Naeem et al. 2000, Moorthi et al. 2008, J. Filip et al. unpubl.) and seagrass beds (Duffy et al. 2003). The positive net biodiversity effect (NBE), which increased with consumer richness in both experiments, was mainly driven by high, positive TIC effects. Positive TIC effects indicate the consumers' ability to occupy different niches and use resources more efficiently (Fox 2005). These positive effects overcompensated the simultaneously occurring negative TDC effects in both experiments (i.e. species with nested niches perform better in mixtures than in monoculture; Fox 2005). These results indicate that positive effects due to the differences between niches and thus increased resource use efficiency were more important than negative effects due to the interspecific competition among the ciliates in mixtures. Even though in both experiments a single consumer species dominated the polycultures (the heterotroph Frontonia in Expt 1 and the mixotroph Coleps in Expt 2), enhanced secondary production at high consumer diversity was mainly due to positive TIC, i.e. a lack of niche overlap, and not due to dominance effects of a single better performing species.

\section{Secondary production is higher in treatments including mixotrophic consumers due to enhanced resource complementarity (Hypothesis 4)}

Consumer biovolume was significantly higher in treatments containing only mixotrophs compared to combined treatments and lowest in heterotrophic ones, although only in Expt 2 (partially confirming Hypothesis 4). The mechanisms driving enhanced secondary production were investigated in previous studies for purely heterotrophic consumers (Gamfeldt et al. 2005, J. Filip et al. unpubl.), demonstrating that secondary production depends on consumer 
richness and traits such as growth and grazing rates as well as food specialization. The present study indicates that increasing trait diversity by alternative nutritional modes, such as mixotrophy, may further increase resource use complementarity and thus secondary production. Considering species contributions to total ciliate biovolume, the mixotroph Coleps was the dominating species in 2- and 4-species assemblages. Photosynthesis through algal symbionts plays a larger role for the growth and biovolume production of Coleps than the mainly phagotrophic Euplotes daidaleos, for which photosynthesis is mainly a survival mechanism when prey is limited (S. Moorthi unpubl. data). Apparently, Coleps successfully supplemented its phagotrophic nutrition with carbon fixation through photosynthesis, gaining a competitive advantage over the other consumers that competed for prey. Previous studies demonstrated that mixotrophs may coexist or even outcompete heterotrophs when light and nutrients are sufficient for photosynthesis but prey becomes limiting (Rothhaupt 1996, Jones 2000). In Expt 1, however, the biovolume production of Coleps was low, and this species was not a very strong competitor with algae for nutrients and with other ciliates for prey. In this experiment, no significant effects of consumer nutritional mode on secondary production were observed. However, a positive net biodiversity effect occurred, which was higher for heterotrophic consumer combinations than for mixotrophic ones and lowest in combined species combinations. Due to the costs of maintaining the physiological apparatus for both photosynthesis and phagotrophy, mixotrophs may have lower grazing and growth rates compared to purely heterotrophic or purely phototrophic organisms under certain conditions (Rothhaupt 1996, and see review by Raven 1997). This can lead to low biovolume production and a weaker overall impact on ecosystem functions (Stickney et al. 2000). However, both experiments were conducted under the same light and nutrient conditions. Therefore, the different effects of mixotrophs on secondary production must have been due to altered competitive interactions among mixotrophs and heterotrophs resulting from different algal and ciliate species compositions. In Expt 2, the very strong grazer Frontonia was substituted with the specialist consumer Nassula, while the diatom Fragilaria capucina and the chlorophyte Eudorina elegans were replaced by another diatom (Navicula pelliculosa) and a filamentous cyanobacteria (Plectonema sp.). As Coleps became dominant in Expt 2 not only in consumer combinations where the strong competitor Frontonia was replaced by Nassula but also in combination with the other heterotophic grazer Stylonychia, altered competitive interactions with the other consumers for prey and with the algal prey for nutrients determined the observed patterns.

In sum, the present study demonstrated that enhancing trait diversity by alternative nutritional modes, such as mixotrophy, may have a positive effect on secondary production but that such effects depend on the composition at both consumer and prey levels. Altered algal and consumer compositions may change competitive interactions on either level, favoring mixotrophs in their secondary production or not. However, in both experiments, a lack of niche overlap among the included species indicated a complementary resource use and led to positive net biodiversity effects at higher consumer richness.

Overall, the present study highlights the importance of algal and consumer species traits, such as growth and grazing rates, consumer specialization and nutritional mode, in determining the effects of consumer diversity loss on food web dynamics.

Our study aimed at gaining a mechanistic understanding of the relevance of consumer specialization and the trophic interactions involved in effects of consumer diversity loss within and across trophic levels. To address different potential mechanisms, it was necessary to include all consumer monocultures to assess consumer specific growth and grazing characteristics, and this was only feasible in a low diversity system. Thus, we explicitly traded naturally high diversity levels in favor of a full design allowing all 1 , 2 and 4 consumer species combinations and thus the detection of specific mechanisms driving biodiversity loss effects. Nevertheless, we consider our experiments to have relevance for natural systems and the mechanisms we observed to play a role in natural food webs with a higher diversity. Other studies have demonstrated that data derived from small-scale experimental studies are useful and important for the analysis and understanding of large-scale ecological patterns. Smith et al. (2005), for instance, investigated the scale dependence of phytoplankton diversity by analyzing published data from a wide range of natural aquatic ecosystems down to small outdoor mesocosms and tiny laboratory microcosms. They found a strong coherence in the relationship between phytoplankton species richness and ecosystem surface area in both natural and artificial systems, concluding that model aquatic ecosystems can successfully inform us about potential determinants of biodiversity change at the whole-ecosystem level. Striebel et al. (2009) investigated the effect of phytoplankton diversity on primary production with spe- 
cial emphasis on resource use complementarity due to different photosynthetically active pigments. They manipulated species richness in artificially assembled low diversity laboratory experiments, revealing that taxon richness increased pigment richness, leading to a more efficient harvesting of the spectrum of solar energy and thus higher primary production. These results were confirmed in the subsequent analysis of the relationship of taxon and pigment richness on primary production in a variety of different natural lake systems. Striebel et al. (2009) therefore emphasized that a conclusive, mechanistic understanding of the influence of biodiversity on ecosystem functioning requires the a priori identification of species traits, in this case conveying complementarity in resource use.

Likewise, our study revealed mechanisms that may lead to higher secondary production due to higher consumer trait diversity (i.e. consumer specialization and nutritional mode) and thus resource use complementarity. It also enhanced our mechanistic understanding of potential effects of consumer diversity on prey dynamics, emphasizing the importance of consumer specific traits, such as growth and grazing rates as well as specialization and nutritional mode.

Acknowledgements. This work was supported by the German Science Foundation (DFG grant MO 1931/1-1).

\section{LITERATURE CITED}

Azam F, Fenchel T, Field JG, Gray JS, Meyer LA, Thingstad $\mathrm{F}$ (1983) The ecological role of water column microbes in the sea. Mar Ecol Prog Ser 10:257-263

Cardinale BJ, Matulich KL, Hooper DU, Byrnes JE and others (2011) The functional role of producer diversity in ecosystems. Am J Bot 98:572-592

> Chan F, Pace ML, Howarth RW, Marino RM (2004) Bloom formation in heterocystic nitrogen-fixing cyanobacteria: the dependence on colony size and zooplankton grazing. Limnol Oceanogr 49:2171-2178

Diller WF, Kounaris D (1966) Description of a zoochlorellabearing form of Euplotes, E. daidaleos n. sp. (Ciliophora, Hypotrichida). Biol Bull (Woods Hole) 131:437-445

$>$ Duffy JE, Richardson JP, Canuel EA (2003) Grazer diversity effects on ecosystem functioning in seagrass beds. Ecol Lett 6:637-645

Finke DL, Snyder WE (2008) Niche partitioning increases resource exploitation by diverse communities. Science 321:1488-1490

Fox JW (2005) Interpreting the 'selection effect' of biodiversity on ecosystem function. Ecol Lett 8:846-856

> Gamfeldt L, Hillebrand H (2011) Effects of total resources, resource ratios, and species richness on algal productivity and evenness at both metacommunity and local scales. PLoS ONE 6:e21972

> Gamfeldt L, Hillebrand H, Jonsson PR (2005) Species rich- ness changes across two trophic levels simultaneously affect prey and consumer biomass. Ecol Lett 8:696-703

Gobler CJ, Davis TW, Coyne KJ, Boyer GL (2007) Interactive influences of nutrient loading, zooplankton grazing, and microcystin synthetase gene expression on cyanobacterial bloom dynamics in a eutrophic New York lake. Harmful Algae 6:119-133

Gragnani A, Scheffer M, Rinaldi S (1999) Top-down control of cyanobacteria: a theoretical analysis. Am Nat 153: $59-72$

Hillebrand H (2003) Opposing effects of grazing and nutrients on diversity. Oikos 100:592-600

Hillebrand $\mathrm{H}$, Durselen CD, Kirschtel D, Pollingher U, Zohary T (1999) Biovolume calculation for pelagic and benthic microalgae. J Phycol 35:403-424

Hillebrand H, Shurin JB (2005) Biodiversity and aquatic food webs. In: Belgrano A, Scharler UM, Dunne J, Ulanowicz RE (eds) Aquatic food webs: an ecosystem approach. Oxford University Press, Oxford, p 184-197

Holen DA, Boraas ME (1995) Mixotrophy in chrysophytes. In: Sandgren CD, Smol JP, Kristiansen JJ (eds) Chrysophyte algae. Cambridge University Press, Cambridge, p 119-140

Hooper DU, Chapin FS, Ewel JJ, Hector A and others (2005) Effects of biodiversity on ecosystem functioning: a consensus of current knowledge. Ecol Monogr 75:3-35

Jaschinski S, Floder S, Sommer U (2010) Consumer identity, abundance and nutrient concentration affect epiphyte diversity in an experimental eelgrass system. Oikos 119: 1745-1754

Jones RI (1994) Mixotrophy in planktonic protists as a spectrum of nutritional strategies. Mar Microb Food Webs 8: $87-96$

Jones RI (2000) Mixotrophy in planktonic protists: an overview. Freshw Biol 45:219-226

- McFadden GI, Melkonian M (1986) Use of hepes buffer for microalgal culture media and fixation for electron microscopy. Phycologia 25:551-557

McGrady-Steed J, Harris PM, Morin PJ (1997) Biodiversity regulates ecosystem predictability. Nature 390:162-165

- Mikola J (1998) Effects of microbivore species composition and basal resource enrichment on trophic-level biomasses in an experimental microbial-based soil food web. Oecologia 117:396-403

> Moorthi SI, Hillebrand H, Wahl M, Berninger UG (2008) Consumer diversity enhances secondary production by complementarily effects in experimental ciliate assemblages. Estuaries Coasts 31:152-162

Naeem S, Hahn DR, Schuurman G (2000) Producerdecomposer co-dependency influences biodiversity effects. Nature 403:762-764

- Naeem S, Li S (1998) Consumer species richness and autotrophic biomass. Ecology 79:2603-2615

Naeem S, Thompson LJ, Lawler SP, Lawton JH, Woodfin RM (1994) Declining biodiversity can alter the performance of ecosystems. Nature 368:734-737

Norberg J (2000) Resource-niche complementarity and autotrophic compensation determines ecosystem-level responses to increased cladoceran species richness. Oecologia 122:264-272

> Pereira HM, Leadley PW, Proença V, Alkemade R and others (2010) Scenarios for global biodiversity in the 21st century. Science 330:1496-1501

Proulx M, Pick FR, Mazumder A, Hamilton PB, Lean DRS (1996) Experimental evidence for interactive impacts of 
human activities on lake algal species richness. Oikos 76 : 191-195

Ptacnik R, Moorthi SD, Hillebrand H (2010) Hutchinson reversed, or why there need to be so many species. In: Woodward G (ed) Integrative ecology: from molecules to ecosystems, Vol 43. Elsevier, Oxford, p 1-43

Ptacnik R, Sommer U, Hansen T, Martens V (2004) Effects of microzooplankton and mixotrophy in an experimental planktonic food web. Limnol Oceanogr 49:1435-1445

Raven JA (1997) Phagotrophy in phototrophs. Limnol Oceanogr 42:198-205

Rice WR (1989) Analyzing tables of statistical tests. Evolution 43:223-225

Riemann B, Havskum H, Thingstad F, Bernard C (1995) The role of mixotrophy in pelagic environments. In: Joint $\mathrm{J}$ (ed) Molecular ecology of aquatic microbes. Springer Verlag, Berlin, p 87-114

Rothhaupt KO (1996) Laboratory experiments with a mixotrophic chrysophyte and obligately phagotrophic and photographic competitors. Ecology 77:716-724

Sanders RW (1991) Mixotrophic protists in marine and freshwater ecosystems. J Eukaryot Microbiol 38:76-81

Shurin JB (2001) Interactive effects of predation and dispersal on zooplankton communities. Ecology 82:3404-3416

Smith VH, Foster BL, Grover JP, Holt RD, Leibold MA, deNoyelles F (2005) Phytoplankton species richness scales consistently from laboratory microcosms to the world's oceans. Proc Natl Acad Sci USA 102:4393-4396

Editorial responsibility: Robert Sanders, Philadelphia, Pennsylvania, USA
Stickney HL, Hood RR, Stoecker DK (2000) The impact of mixotrophy on planktonic marine ecosystems. Ecol Modell 125:203-230

> Stoecker DK (1998) Conceptual models of mixotrophy in planktonic protists and some ecological and evolutionary implications. Eur J Protistol 34:281-290

Stoecker DK, Gifford DJ, Putt M (1994) Preservation of marine planktonic ciliates: losses and cell shrinkage during fixation. Mar Ecol Prog Ser 110:293-299

Striebel M, Behl S, Diehl S, Stibor H (2009) Spectral niche complementarity and carbon dynamics in pelagic ecosystems. Am Nat 174:141-147

Thébault E, Loreau M (2003) Food-web constraints on biodiversity-ecosystem functioning relationships. Proc Natl Acad Sci USA 100:14949-14954

Tilman D, Downing JA (1994) Biodiversity and stability in grasslands. Nature 367:363-365

Tilman D, Reich PB, Knops J, Wedin D, Mielke T, Lehman C (2001) Diversity and productivity in a long-term grassland experiment. Science 294:843-845

Trenbath BR (1974) Biomass productivity of mixtures. Adv Agron 26:177-210

Utermöhl H (1958) Zur Vervollkommnung der quantitativen Phytoplankton-Methodik. Mitt Int Ver Theor Angew Limnol 9:1-38

Wardle DA (1999) Is 'sampling effect' a problem for experiments investigating biodiversity-ecosystem function relationships? Oikos 87:403-407

Submitted: October 19, 2011; Accepted: May 3, 2012

Proofs received from author(s): June 30, 2012 